Prophylaxe

\section{Lassen Sie Ihre Patienten zugreifen}

Regelmäßig verzehrt reduzieren die miradent Xylitol Chewing Gums nachhaltig die Plaquebildung auf der Zahnoberfläche. Die Kaugummis sind zu mit 100\% Xylitol gesüßt, ganz ohne Haushaltszucker, wie z. B. Saccharose. Die Marke miradent setzt dabei auf hochwertige Rohstoffe und verzichtet deshalb vollständig auf die Inhaltsstoffe Aspartam und Sorbitol. Der Inhaltsstoff Xylitol wird für die Herstellung ohne den Einsatz von Gentechnik sauber gewonnen. Das Produkt ist ebenfalls frei von Gluten, Lactose und Fructose.
Der Kaugummi ist in den Geschmackrichtungen Spearmint, Pfefferminz, Zimt, Frucht, Cranberry und Grüner Tee in einer Dose mit je 30 Stück, sowie in einer 6-fach sortierten Schüttverpackung (200 x 2 Dragees) erhältlich. Ab sofort können Interessenten an einer miradent Xylitol Chewing Gums Testaktion teilnehmen. Die ersten 100 Teilnehmer erhalten eine Xylitol Chewing Gum Schüttbox mit jeweils 50 x 2 Dragees. Nach einer Zeit von 4 Wochen wird gebeten, einen beiliegenden Fragebogen zurückzusenden.

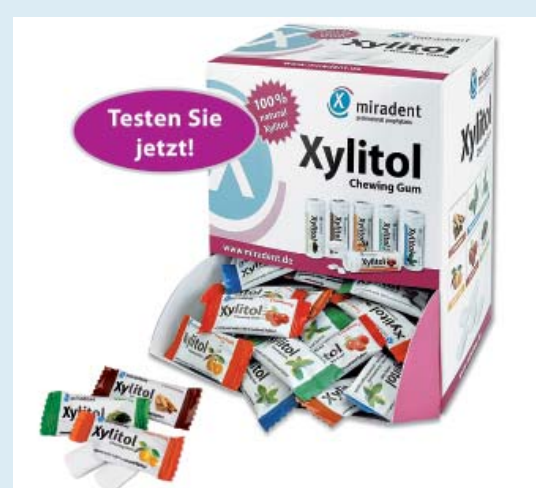

Nach einer Pressemitteilung der Hager \& Werken GmbH \& Co. KG, Duisburg Internet: www.hagerwerken.de 